\title{
Enhanced Assessment of the Remaining Service Life of a Steel Railway Bridge
}

\author{
John Leander ${ }^{1, a}$, Andreas Andersson ${ }^{1, b}$ and Raid Karoumi ${ }^{1, c}$ \\ ${ }^{1}$ The Royal Institute of Technology (KTH), Stockholm, Sweden \\ ajohn.leander@byv.kth.se, ${ }^{b}$ andreas.andersson@byv.kth.se, 'craid.karoumi@byv.kth.se
}

Keywords: railway bridge, fatigue, monitoring, bridge assessment.

\begin{abstract}
During annual inspections of one of Sweden's most important railway bridges, the Söderström Bridge in central Stockholm, cracks in the web of the main steel beams have been discovered. Extensive theoretical work has been undertaken to assess the remaining service life of the bridge. Furthermore, the bridge has recently been instrumented to enhance the theoretical predictions by monitoring the real railway traffic as well as the response of the bridge. This article describes the monitoring program and the analysis methods used. Some interesting results regarding the remaining fatigue life are presented.
\end{abstract}

\section{Introduction}

In last decades, the traffic loads and speeds on the Swedish railway network has drastically increased due to demands of the continually growing economy and higher transport efficiency. As a consequence, many existing railway bridges are now subjected to loads and speeds higher than those for which they have been designed. This accelerates the bridge deterioration process and eventually increasing maintenance costs and decreasing the service life of bridge structures. To make an enhanced assessment of a bridge structure, the actual condition of the structure and its true behavior need to be evaluated by testing and monitoring. In [1] Frangopol states that monitoring programs are necessary due to uncertainties in environmental and mechanical conditions, material properties, and loading history, among others when assessing bridges.

During annual inspections of one of Sweden's most important railway bridges, the Söderström Bridge in central Stockholm, cracks in the web of the main steel beams have been discovered. Analytical fatigue assessment according to Andersson [2] has stated that several sections are crucial for the remaining service life of the bridge, with the highest damage rate in the stringers. However, the inspections have not shown any fractures in the stringers.

An extensive monitoring program has been initiated to more accurately assess the bearing capacity of the bridge and to validate the analytical calculations.

This article describes the monitoring program and the analysis methods used. Some interesting results regarding the remaining fatigue life are presented.

\section{The Bridge}

The Söderström Bridge in central Stockholm is situated on the main railway line between the northern and southern parts of Sweden. Its bearing capacity is crucial for freight transports as well as for passenger trains moving into and out from the city of Stockholm. About 520 trains pass the bridge every day.

The bridge consists of a continuous steel grillage in six spans with a total length of $190 \mathrm{~m}$, see Fig. 1. It has two tracks with wooden sleepers resting directly on the stringer beams. The intersection between the main beams and cross beams are skew with an angle of $80^{\circ}$. The supports are numbered from 4 to 10 according to the original drawings. The horizontal alignment of the bridge is straight between support no. 4 to 7 transcending to a constant radius of app. $2500 \mathrm{~m}$ between support no. 7 to 10 . 
The bridge was built around the year of 1950 and designed according to the contemporary codes.

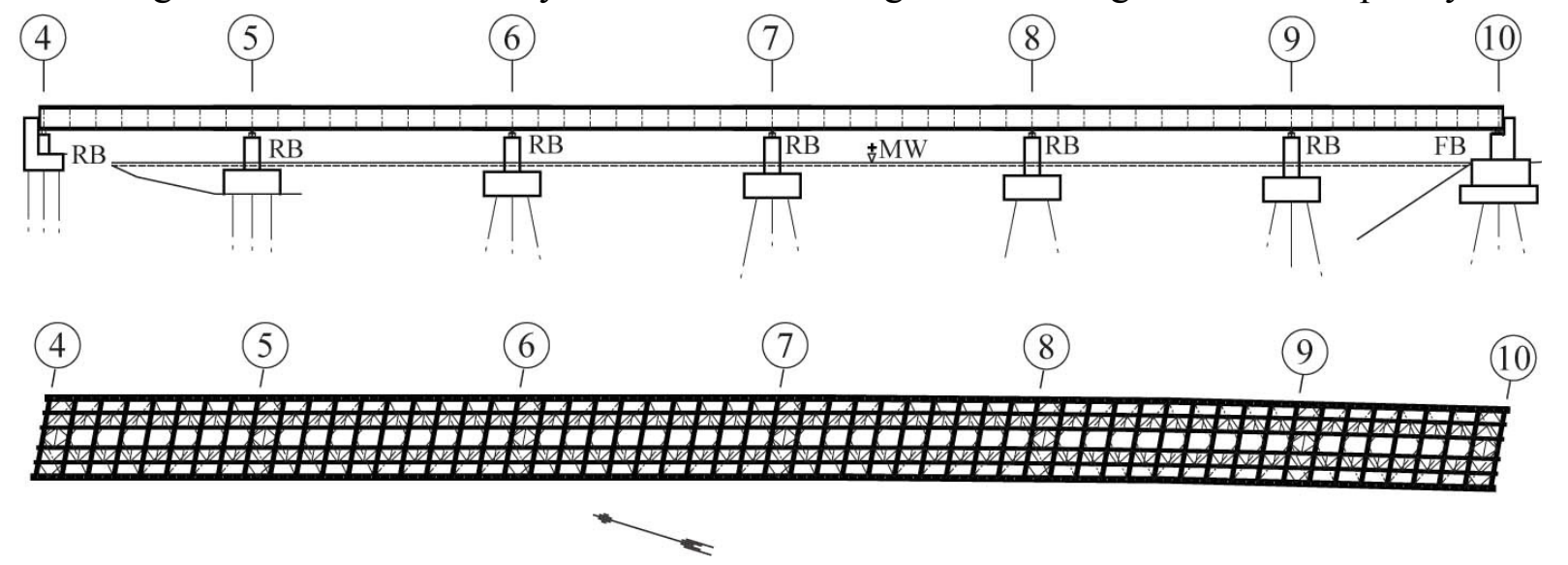

Fig. 1. Elevation and plan of the Söderström Bridge. RB indicates roller bearings and FB indicates fixed bearings.

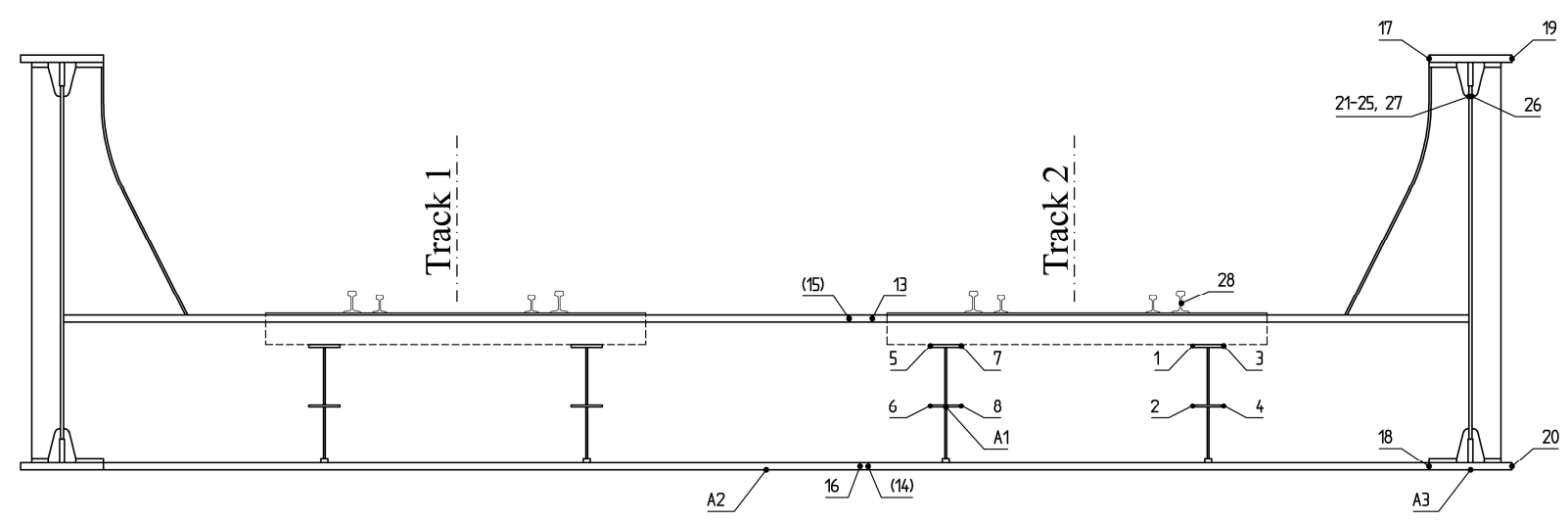

Fig. 2. Cross section of the Söderström Bridge. Typical positions of strain gauges and accelerometers are indicated (accelerometer are numbered starting with an A).

\section{Monitoring program}

An extensive monitoring program has been developed to assess the bearing capacity of the bridge and to validate the analytical calculations. The stringers, crossbeams and the main beams have been instrumented with the total amount of 54 strain gauges and 5 accelerometers. Moreover, the rails have been instrumented with two strain gauges to investigate the interaction between the rail and the stringer. On the main beams, gauges are placed both on the flange edges and on the web near the discovered fractures. The gauges on the web are arranged for measurement of hot spot stresses.

A detailed description of all instrumentation and the installation procedures used in this project is given by Leander [3].

The installed system was calibrated using one Swedish RC-locomotive having known weight and axle distances. Several tests with speeds ranging from $1 \mathrm{~km} / \mathrm{h}$ to about $80 \mathrm{~km} / \mathrm{h}$ were made, partly for investigating the influence of the dynamic response. 


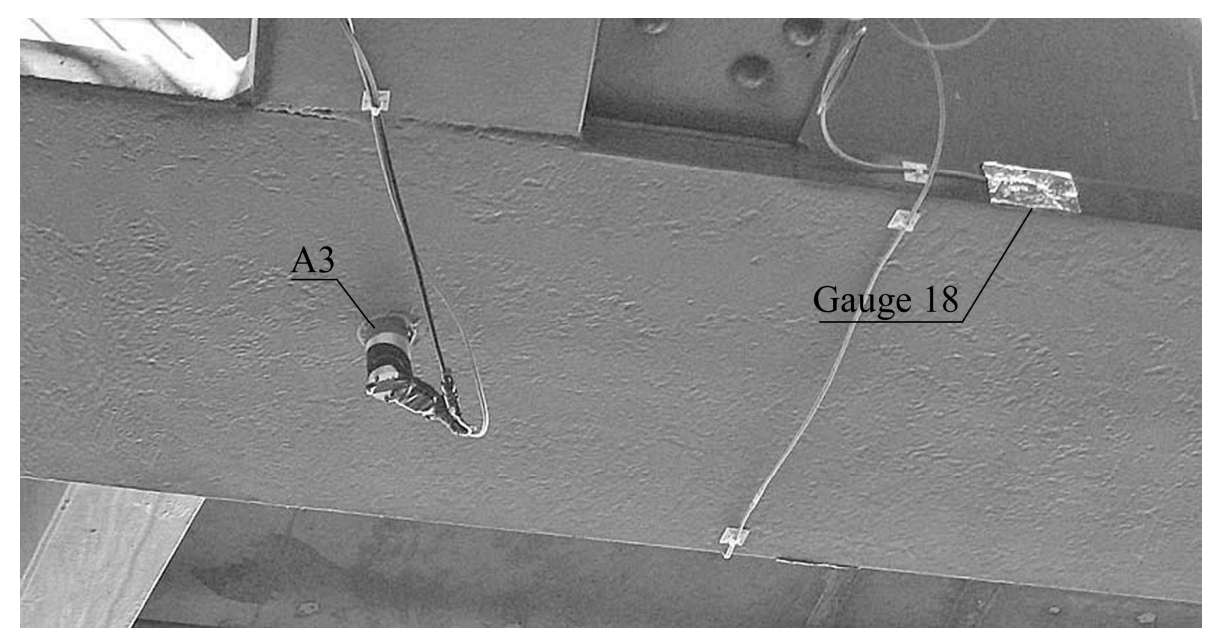

Fig. 3. Accelerometer A3 and strain gauge 18 placed at the bottom flange of the main beam.

\section{Data acquisition}

Continuous measurements were performed round the clock for 43 days. A sample frequency of $400 \mathrm{~Hz}$ was used, rendering a daily data volume of $16 \mathrm{~GB}$. The raw data was stored in 10 minute files on site and the extensive data volume was later post-processed using developed MATLAB ${ }^{\circledR}$-routines. By extracting the train passages, the analyze time for the subsequent calculations could be reduced and the long term effects in the strain signal could be minimized. As the main purpose of the measurements is the fatigue assessment only the strain resulting in stress variation is relevant.

The train extraction was conducted by calculating the strain variation during a fixed time interval. If it exceeded a given threshold value the time interval assumed to withhold a train passage. Statistical data for example time, the duration of the passage, the speed of the passage and the maximum strain variation for every gauge were calculated for every registered train passage. A statistical evaluation was performed for sorting out passages with abnormal values so that they could be checked manually. During the 43 days of measurements, a total of 17371 train passages were registered. Only two of them were discharged due to abnormal strain levels which were created by electric disturbance.

\section{Fatigue assessment}

The fatigue assessment based on the monitoring data was performed according to Palmgren-Miner's cumulative damage rule. The stress range spectrums were generated using the Rainflow cycle counting method [4] on the measured strains.

Even in the routines for the cycle counting, statistics of stress levels and total number of cycles per passage were saved. It facilitated a secondary check of the measured data to sort out abnormal passages.

The detail classification of the structural connections is decisive for the resulting fatigue life. The classification has been done according to the Eurocode EN-1993-1-9 [5] where the categories that best match the real details have been chosen. The constant detail category $C$ varies from 40 to 100 for the regarded sections. Fig. 4 shows the used S-N-curves for the two extremities. 

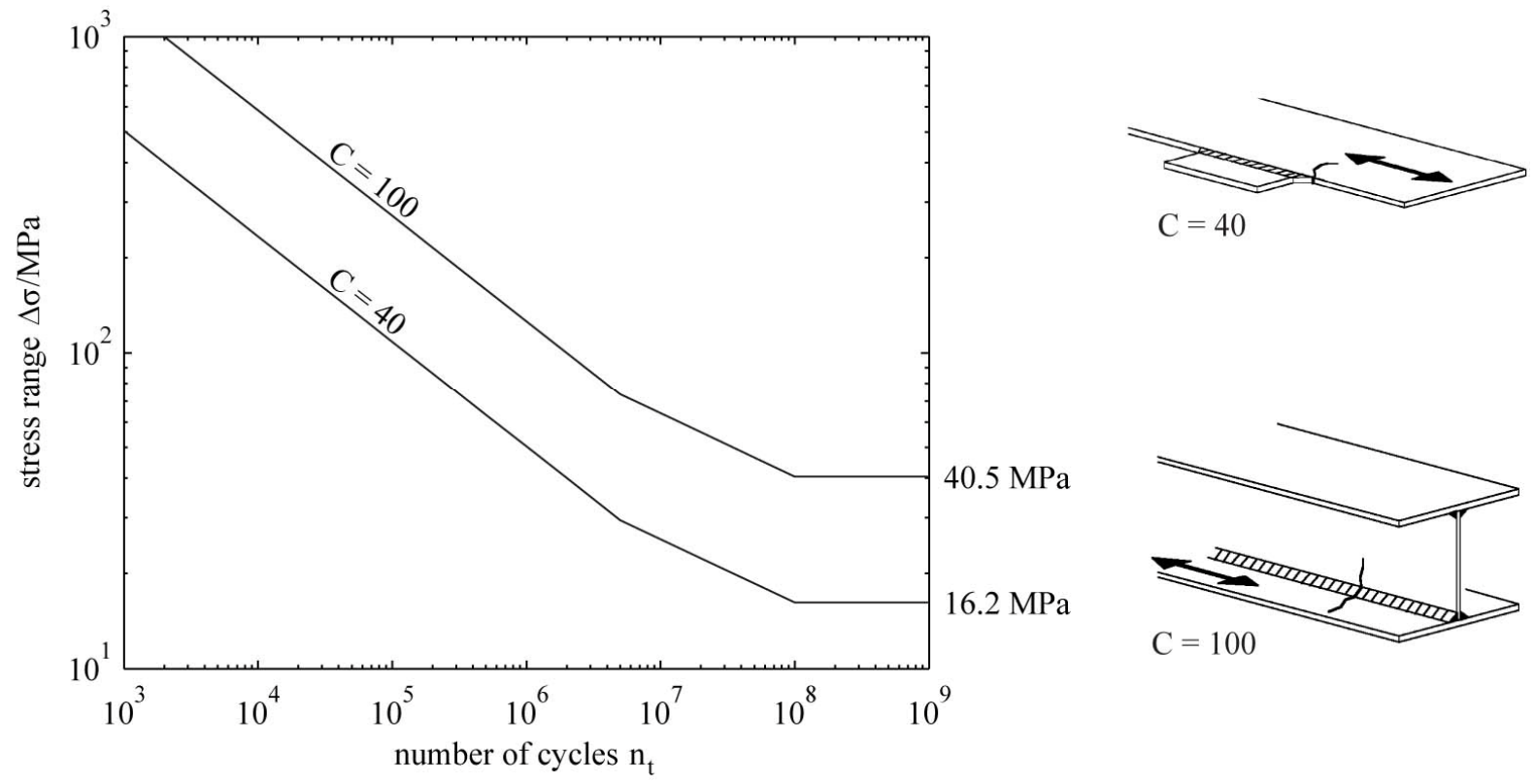

$\mathrm{C}=40$

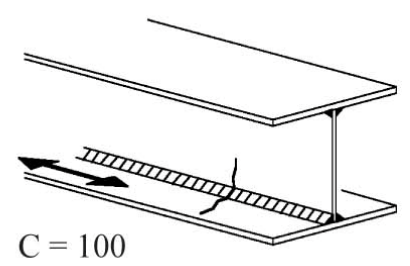

Fig. 4. S-N-curve for the detail categories $C=40$ and $C=100$. The figures on the right side are copied from [5] and reflect the assumed fracture mode.

\section{Results}

Strains, stresses and remaining fatigue life have been studied in the sections marked from A to $\mathrm{J}$ in Fig. 5. In the following, results for section $G$ are presented and in particular for gauge 35 located at the upper flange of the stringer (corresponding to gauge 7 in Fig. 2, though in a different section).

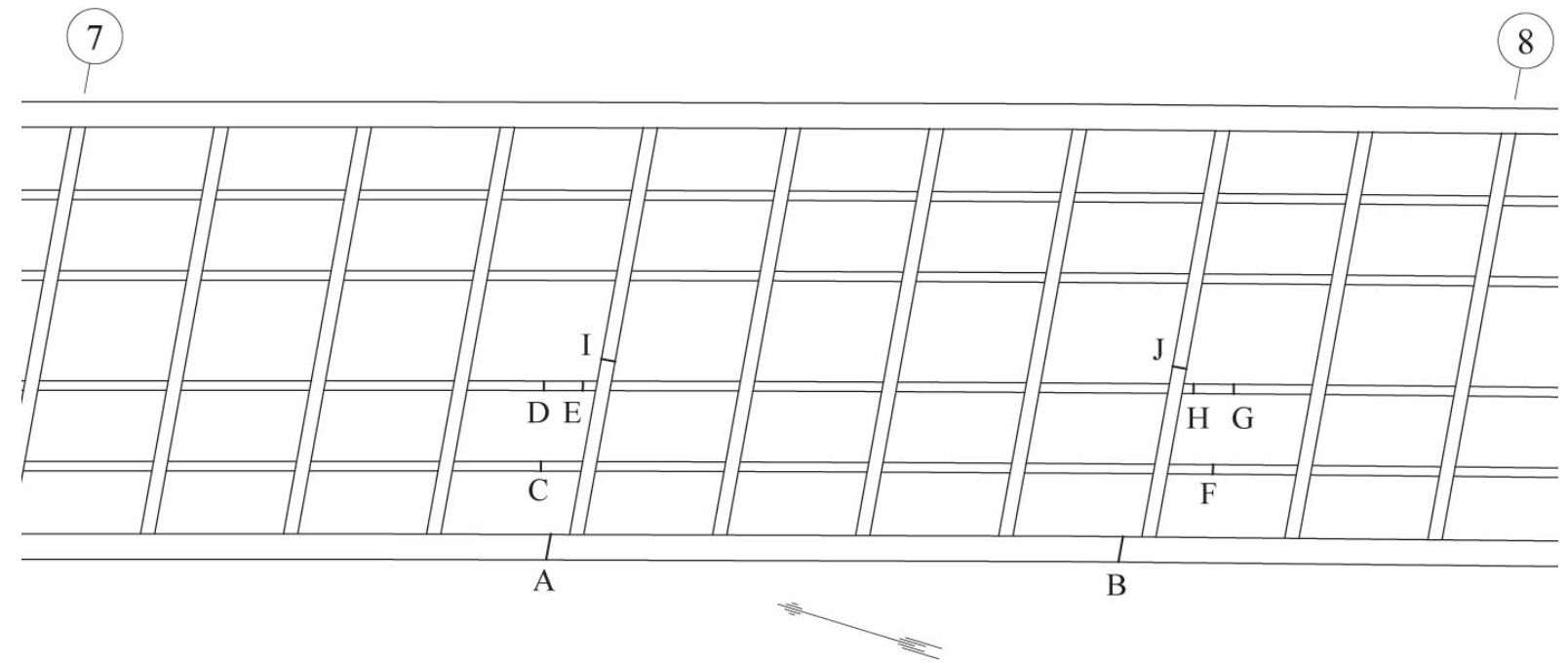

Fig. 5. Detailed plan of the bridge with the considered sections marked A to J.

Fig. 6 shows the strain variation in the stringer of section $G$ for a passage of a Swedish commuter train of type X60, which is the most frequent train load on the bridge. Stresses are calculated by multiplying the strain values with the Young's modulus.

The result of the cycle counting calculations for the complete monitoring period is shown in Fig. 7. The spectrum is shown both as a histogram and a stress range spectrum. 


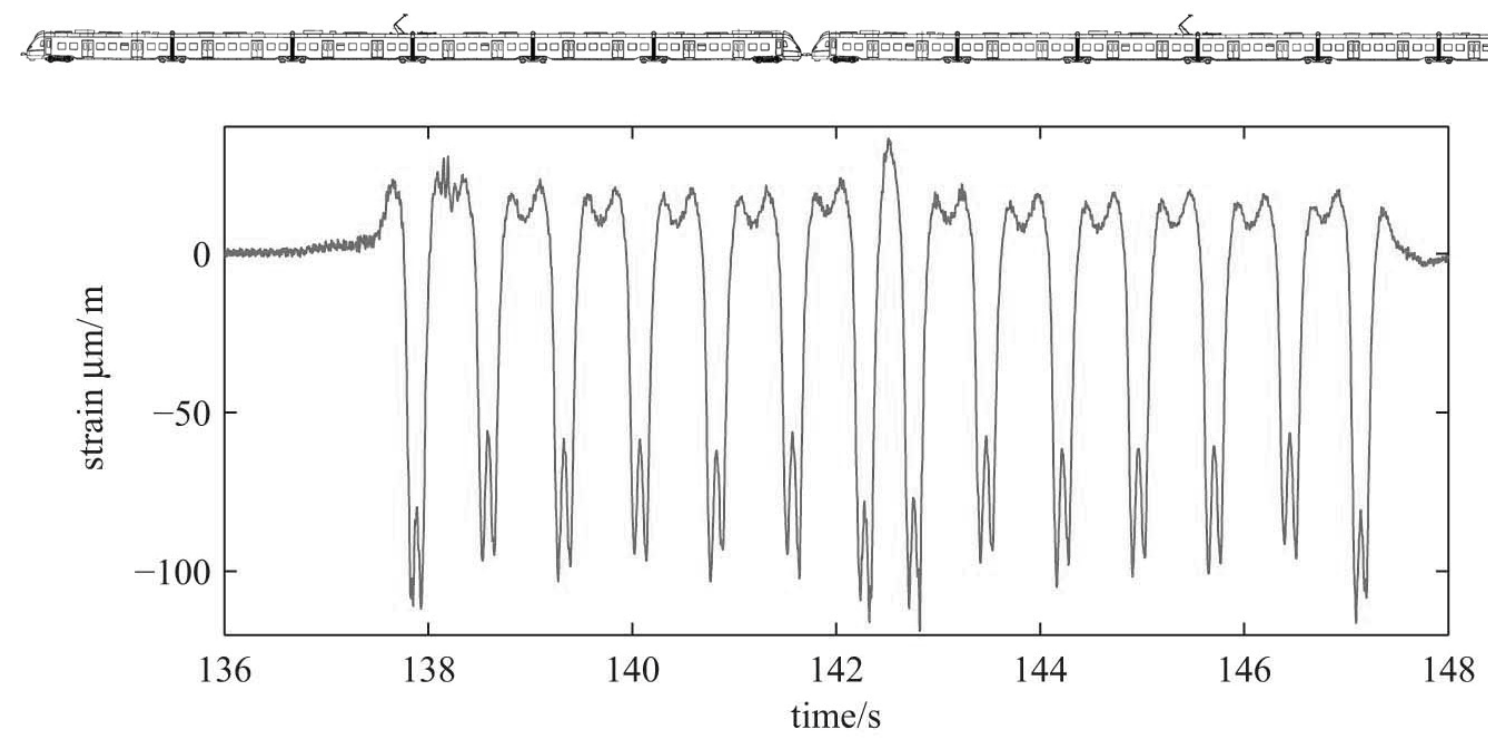

Fig. 6. Measured strain in gauge 35 for a passage of a Swedish commuter train of type X60, illustrated in the upper figure.
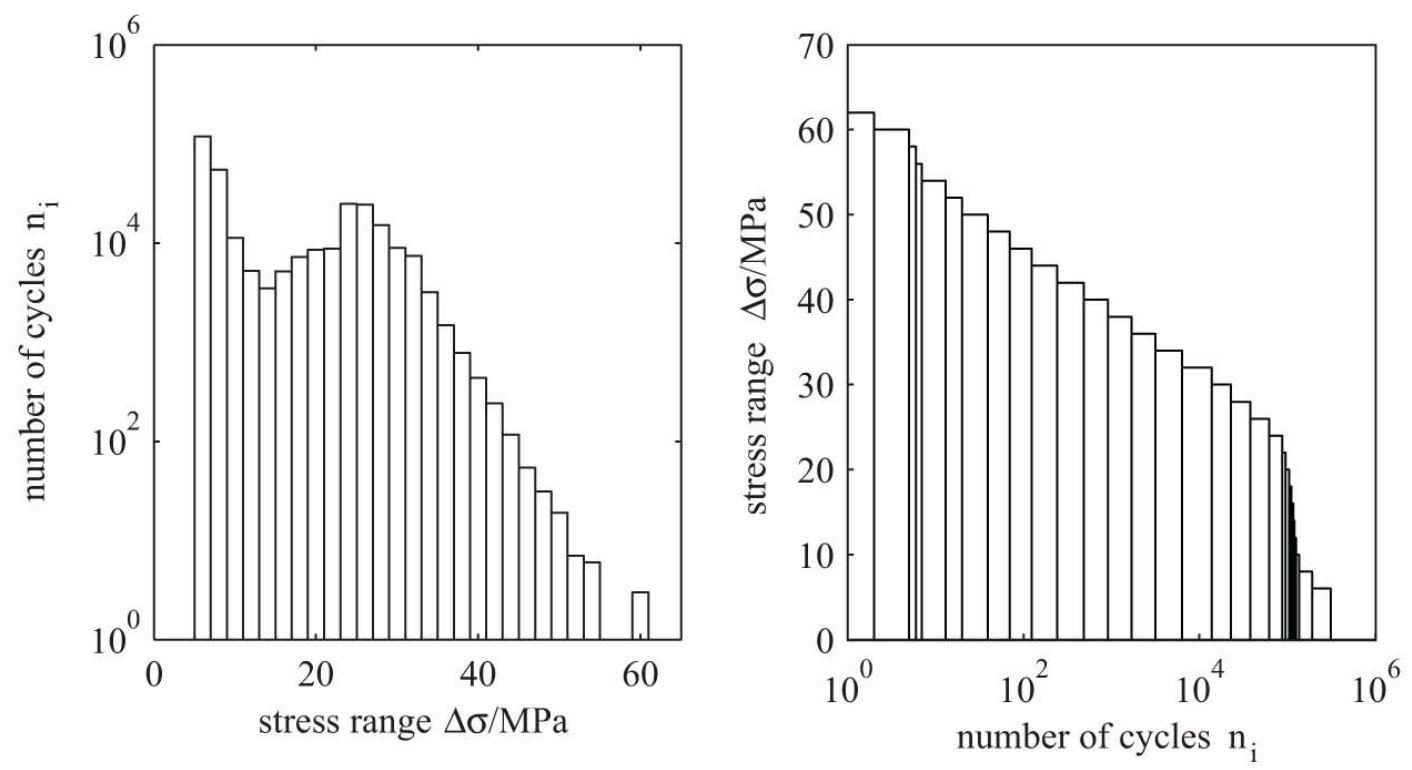

Fig. 7. The result of the Rainflow analysis shown as a histogram and a stress range spectrum for gauge 35 .

The result of the cumulative damage calculations for gauge 35 is shown in Fig. 8. The large number of cycles in the stress range around $25 \mathrm{MPa}$ is causing the high level of cumulative damage. Almost every train passage cause some cycles with stress ranges around $25 \mathrm{MPa}$. However, the amount of commuter trains and the fact that their axle loads are almost identical is the main reason for the high damage.

The rather few cycles with high stress range gives a relatively small contribution to the resulting damage. 


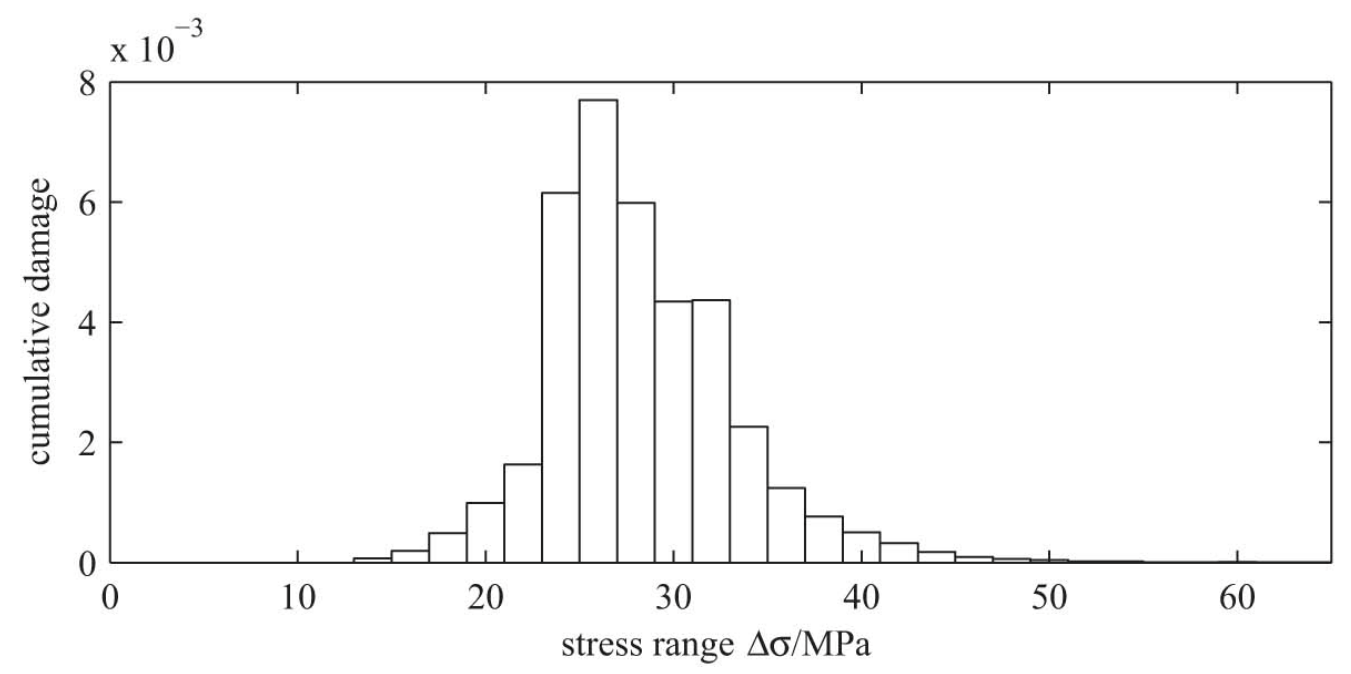

Fig. 8. The result of the cumulative damage calculation of gauge 35 according to Palmgren-Miner's rule.

By summarizing the damages for each stress range in Fig. 8 the total damage for the measuring period is achieved.

According to statistics from the Swedish Railroad Administration (Banverket), an average of 527 trains passes the bridge every day. By multiplying the calculated damage by a quotient of the expected number of passages and the number of registered passages, the total yearly damage is achieved. For gauge 35 , the damage during the measuring period is 0,037 . The yearly damage is estimated to 0,411 , indicating a theoretical remaining fatigue life of merely 2 years, assuming constant traffic load and no fatigue damage in the present. The result shows that the fatigue life has been exceeded substantially since the bridge was built.

Table 1 shows the damage for all gauges in section G. It can be seen that for gauges with a detail category $C=100$ the damage is negligible. The choice of detail class $C=40$ is made because of the cross bracing connections to the upper flange of the stringers.

The result of a parametric study of $C$ is shown in Fig. 9 where $D_{\text {year }}$ is the damage per year and $\alpha_{\mathrm{C}}=C / 40$. The asymptotic shape of the curve results in fast increasing damage with decreasing $C$.

\begin{tabular}{|c|c|c|c|c|}
\hline gauge & position & $C$ & damage/m.p. & damage/year \\
\hline 33 & upper flange & 40 & 0,0146 & 0,1610 \\
34 & lower flange & 100 & 0,0000 & 0,0001 \\
35 & upper flange & 40 & 0,0374 & 0,4119 \\
36 & lower flange & 100 & 0,0002 & 0,0020 \\
\hline
\end{tabular}

Table 1: Calculated damage next to the gauges in section $\mathrm{G}$. 


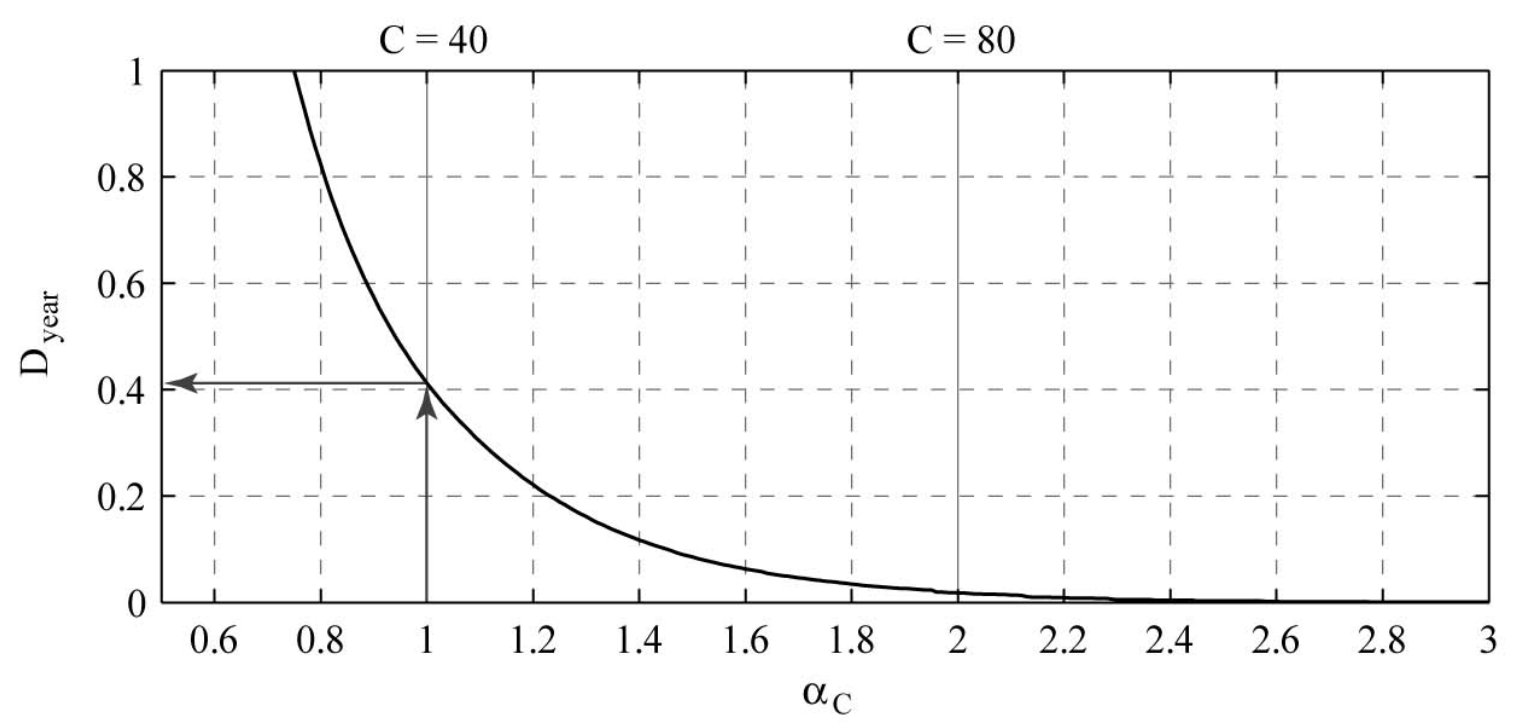

Fig. 9. Parametric study of the detail category $C$.

\section{Conclusions}

Cracks in the web of the main steel beams of the Söderström Bridge in central Stockholm have been discovered. Extensive monitoring of the structural behavior have been undertaken to enhance the assessment of the remaining service life of the bridge. The following conclusions are based on the results of the instrumentation and monitoring program:

- The monitoring program gives reliable and adequate results for bridge assessment. To take advantage of the extensive amount of collected data, efficient routines are a condition.

- For the studied bridge, the resulting cumulative damage shows that more detailed analyses and short inspection intervals are necessary. The bridge has been in service for over fifty years and has well past the theoretical service life. To explain the lack of discovered fractures on the stringers it is necessary to calculate an expected crack width.

- The origin of the discovered fractures in the main beams has not been studied within the scope of this paper. However, the fractures are considered to be of little importance for the capacity of the bridge and are a consequence of a poorly designed connection between the main beams and cross beams.

\section{Acknowledgements}

The funding for this project is provided by the Swedish Rail Administration (Banverket) and is gratefully acknowledged. The authors of this paper would also like to thank the KTH laboratory technicians Stefan Trillkott and Claes Kullberg for the excellent installation work of the monitoring system.

\section{References}

[1] D. M. Frangopol and A. Strauss and S. Kim: Bridge Reliability Assessment Based on Monitoring, Journal of Bridge Engineering, ISSN 1084-0702, Volume 13, Number 3, May/June 2008.

[2] A. Andersson: Utmattningsanalys av järnvägsbroar (Fatigue Assessment of Railway Bridges). Licentiate Thesis in Strucutral Design and Bridges, the Royal Institute of Technology (KTH), Stockholm, 2008. (in Swedish, in press) 
[3] J. Leander: The bridge over Söderström, measurements and evaluation considering fatigue, TRITA-BKN. Report 126, Structural Design and Bridges, ISSN 1103-4289, the Royal Institute of Technology (KTH), Stockholm, 2008. (in Swedish)

[4] M. Matsuishi and T. Endo: Fatigue of Metals Subjected to Varying Stress, paper presented to the Japan Society of Mechanical Engineers, Fukuoka, Japan, March 1968.

[5] Eurocode 1993-1-9: Design of steel structures, Part 1.9: Fatigue, European standard, CEN, 2003. 


\section{Damage Assessment of Structures VIII}

doi:10.4028/www.scientific.net/KEM.413-414

\section{Enhanced Assessment of the Remaining Service Life of a Steel Railway Bridge} doi:10.4028/www.scientific.net/KEM.413-414.245

\section{References}

[1] D. M. Frangopol and A. Strauss and S. Kim: Bridge Reliability Assessment Based on Monitoring, Journal of Bridge Engineering, ISSN 1084-0702, Volume 13, Number 3 , May/June 2008.

[2] A. Andersson: Utmattningsanalys av järnvägsbroar (Fatigue Assessment of Railway Bridges). Licentiate Thesis in Strucutral Design and Bridges, the Royal Institute of Technology (KTH), Stockholm, 2008. (in Swedish, in press)

[3] J. Leander: The bridge over Söderström, measurements and evaluation considering fatigue, TRITA-BKN. Report 126, Structural Design and Bridges, ISSN 1103-4289, the Royal Institute of Technology (KTH), Stockholm, 2008. (in Swedish)

[4] M. Matsuishi and T. Endo: Fatigue of Metals Subjected to Varying Stress, paper presented to the Japan Society of Mechanical Engineers, Fukuoka, Japan, March 1968.

[5] Eurocode 1993-1-9: Design of steel structures, Part 1.9: Fatigue, European standard, CEN, 2003. 